\title{
THE ROLE OF IBM IN STARTING UP COMPUTING IN THE NORDIC COUNTRIES
}

\author{
Hans E. Andersin \\ Professor Emeritus, Helsinki University of Technology; hans.andersin@hut.fi
}

\begin{abstract}
This paper explores the role of early IBM strategies such as installing "computing work horses" at various customer and own sites for shared use. It did this by making available a "super computer" at the Northern Europe University Computing Center, by making available programming languages and application programs to the computing community, and, not least, by conducting courses in state-of-the-art equipment and computing methods. The paper covers the time up to the advent of the IBM System 360 in 1964.
\end{abstract}

Keywords: IBM, scientific computing, data processing, competition, Nordic countries

\section{THE UNDISPUTED LEADER IN ADMINISTRATIVE DATA PROCESSING}

The US based company International Business Machines (founded in 1911) had achieved by the beginning of the computer era a dominating position worldwide in the field of punched card data processing [1], [3]. IBM punched card equipment was everywhere, in state and local government, in companies, and in military installations. It sometimes utilized the latest developments in electronic circuitry. Competition was only marginal.

The competitive situation changed when electronic computers appeared on the administrative data processing scene. For a short period, the competitors of IBM were in the lead. IBM then tried to win time by making programmable punched card machines and sophisticated electronic calculators available. When it got its first large-scale administrative data 
processing machines - the IBM 702 followed by the IBM 705 - on the market, the battle against the competition started, soon to be won by IBM, thanks largely to the large and loyal customer base of the company. For smaller customers, the advent of the IBM 650 (announced in 1953, but first installed in the Nordic countries in 1956) and several innovations like the random access method of accounting and control computer RAMAC (first delivery in 1957) paved the way. The real success came with the IBM 1401, announced in 1959, and first installed in the Nordic countries 1960-1961. This data processing machine was priced to capture the small and medium sized customer market. IBM sold 12000 of these 1401 computers worldwide. The IBM 1440, even smaller and cheaper than the 1401, arrived in 1962. Together with the 1440 came exchangeable disk memories, so called 'disk packs'. A larger and more powerful machine than the 1401 was the IBM 1410, announced in 1960. Customers who wanted powerful handling of the peripherals simultaneously with complex data processing ordered systems consisting of interconnected 1410 and 1401 machines.

Simultaneously with introducing new generations of large- and smallscale data processing machines, IBM developed a number of new devices for them such as fast line printers and card readers, magnetic tape stations, and random access storage devices. It also introduced new concepts like independent smart I/O channels. It developed new tools for the user such as operating systems especially suited to data processing needs. IBM implemented the newly developed COBOL programming language for its data processing machines. The announcement of the IBM System 360 in 1964 marked the end of the period of early computing. From that point on, IBM continued to be the undisputed leader in administrative data processing for several years to come.

Why did this happen? Firstly, IBM had by far the largest and most loyal group of punched card equipment customers. These customers felt comfortable in their dealings with IBM because of good assistance in systems engineering, for example, and with maintenance service and the favorable terms of replacing old rental equipment with new. Secondly, the numerous innovations in hardware and software stemming from the vast IBM laboratory organization made most customers believe that IBM would be able to fill their growing needs well into the future. Thirdly, the IBM customer education was the best and the most extensive you could get. Fourthly, IBM had a devoted and well-managed force of sales representatives and systems engineers. All of this was true in the Nordic countries also. In addition to this, IBM was the only data processing machine manufacturer that had a factory in the Nordic Region exporting equipment from the region. Bull, originally a Norwegian company, had long since moved abroad. Nokia was still to come. In addition, the IBM Nordic Laboratories in Sweden rendered IBM a political competitive advantage. In 
cities in all the Nordic countries, IBM had service bureaus both for getting customers started and for assisting smaller customers who could not afford to have data processing installations themselves. This was the early situation with respect to the administrative data processing market: IBM became the undisputed leader in the Nordic countries.

\section{THE SCIENTIFIC COMPUTING MARKET WAS TOUGHER}

When studying the early steps in the field of scientific computing the picture is not as clear and straightforward as in the administrative data processing field. In all the Nordic countries, scientists and engineers had used IBM punched card calculators (e.g. the electronic IBM 604, announced in 1948). The scientific community was aware of the potential of computing machinery. Many of the scientists had either seen with their own eyes or read about how their colleagues in the USA, Britain and other countries had already built themselves more or less powerful computers already in the 1940s. This was to be the case in the Nordic countries also. Here universities and research facilities constructed scientific computers in the 1950 s ranging from the very powerful BESK-family to some rather unsophisticated small computers. At that time, nobody was even thinking of IBM as a prospective manufacturer of powerful scientific computers at a price that a Nordic University or a research establishment could afford.

IBM had been participating in the earliest development of computing machinery, the electromechanical Mark I (Automatic Sequence Controlled Calculator) at the Harvard University (1944) and the Selective Sequence Electronic Calculator (1948), a computer utilizing both relays and electron tubes. IBM, however, did not realize that scientific computers could have a market of any significance outside perhaps the defense sector and some universities. Furthermore, the IBM sales force had neither experience nor knowledge of selling to the scientific community.

For the defense market, it designed special computers. When IBM's competitors had shown that the market demanded commercially produced computers, IBM decided in 1952 to announce this special "defense calculator" as the IBM 701, performing 17,000 additions per second. IBM delivered nineteen 701 machines to customers and these were followed by deliveries of the more successful IBM 704 (announced in 1955). These machines used vacuum tubes, CRT's, magnetic tape stations, and magnetic drum memories. We called them "computers" in the present sense of the word. This was a turning point for IBM in USA in the field of scientific computing. Many of the US universities and research establishments 
jumped onto the IBM bandwagon. IBM announced the 7090 in 1959, one of the first fully transistorized mainframes; it was able to perform 229,000 additions per second. One of the reasons for IBM's success in USA was the generous Educational Allowance Plan introduced by IBM in USA allowing educational institutions to rent IBM equipment for as low as $40 \%$ of the list price. Later in the 1950s, it introduced this plan outside USA as well.

What worked in the USA did not work in the academic computing field in the Nordic countries! Here the boom of self-built computers continued far into the $1950 \mathrm{~s}$.

\subsection{IBM 650 became the work horse for the engineer as well}

The engineering users as well as the less sophisticated scientific users, however, were more attracted by large libraries of ready programs and systems software than their academic colleagues who often wanted to make all the programs themselves. For the less sophisticated users the medium size computer IBM 650 (announced in USA 1953) was just right. The 650 started delivery to users in the Nordic countries during the second half of the 1950s. It installed the first 650 in an insurance company (Folksam) in Sweden in 1956. Immediately thereafter, scientific and engineering users, among them the author of this paper, from all the other Nordic countries rushed to Stockholm to use the computer and its large library of ready-made programs that was made available to users free of charge. This model was very much the one in which the 650 became in use in the Nordic countries. The main customer was either a large data processing user such as an insurance company (in Sweden) or a bank (in Finland). Sometimes the main customer was a large scientific user such as a geophysics institute (in Norway), while the secondary users were either one or several smaller engineering or data processing users.

One of the main attractions for the engineering community was the new programming language FORTRAN, developed first for the 704 computer, and then for other computers as well by an IBM group of programmers led by John Backus during 1953-1957. FORTRAN was easy to learn and easy to use and became in practice the most used scientific and engineering language for many decades.

The IBM 1620, a small computer for scientific computing, followed the IBM 650. Some universities in the Nordic countries ordered it. A variant of the 1620 , IBM installed the 1710 system for process monitoring and control at a number of plants in the Nordic countries. 


\subsection{Love versus respect}

In the 1950s, a slightly frustrated IBM Applied Science Representative uttered the statement "IBM is not loved but respected". As far as the author remembers, there really existed some animosity between the scientific community and IBM during the early times of computing, at least in the Nordic countries. There were many possible reasons for this. Local IBM sales representatives possessed neither any deep knowledge of scientific computing nor the necessary endurance and motivation to deal with scientist and engineers. In addition, the typical IBM sales representative lacked sufficient insight into computer technology and the theoretical foundations of computing. Some people considered some IBMers arrogant. The IBM company culture that had developed along with the dominance in the punched card business did not please the scientists. The scientific community, who until quite recently had built their own computers, thought that the IBM computers were grossly overpriced. "We do not need all the systems support, software and other 'bells and whistles' that are included in the price" was a common opinion among scientists. When IBM introduced the Educational Allowance Plan for universities, people looked upon it, at least at first, with mistrust because of complicated rules and restrictive clauses. Later the Educational Allowance Plan almost became as an act of unfair competition. IBM's policy of only leasing its systems to the customer was unfamiliar to the scientific community, which was used to the governmental budgeting rules based on outright purchase of equipment.

The respect for IBM came from the fact that many of the Nordic scientists had become acquainted with large-scale 700 and 7000 series IBM machines installed at US universities, research institutions, and industries. Scientists were quite impressed by their visits to IBM plants and laboratories in the USA and Europe. In 1960, IBM unveiled the STRECH computer, the first "super computer". The respect for IBM also originated from IBM's enormous success in administrative data processing. The scientists also envied their US colleagues' apparent abundance of funds allowing for renting large-scale computers while they at home had to get the cheapest available systems. This meant buying mostly non-IBM.

The problems IBM had with its conventional sales force in selling to the scientific community gave rise to a new breed of IBMers, the so-called Applied Science Representatives. The first of the Applied Science Representatives were often people who had taken part in building the first computer in their respective countries. They were, however, seldom skilled and trained in selling to mistrusting academic and engineering customers. 


\subsection{Algol versus FORTRAN, punched cards versus paper tape}

The feud between IBM and its competitors in scientific computing, between IBM and the scientific community, and between practically oriented people such as engineers and computer science oriented people, sometimes took bizarre forms. A part of the scientific community considered FORTRAN, as compared to Algol, a brute force language with insufficient logical structure and complexity. The engineering community and practically oriented scientific computer users did not wait for Algol but started to employ FORTRAN instead and found the language sufficiently usable. IBM continued to support FORTRAN, and their customers continued to use it, for many decades. The universities, however, insisted on teaching Algol and Algol-like languages while continuing to frown upon FORTRAN, even though most of their students were to use FORTRAN in their coming working life.

Another dividing line between the scientific community and IBM was the use of paper tape instead of punched cards as an input and output medium. The paper tape was in some cases more practical and cheaper than punched cards for scientific and engineering applications, but IBM mostly refused to recommend paper tape and forced punched cards upon their customers (with one exception, the electromechanical engineering computer IBM 610). IBM's competitors, on the other hand, did all they could to promote paper tape.

\subsection{Success or failure in scientific computing}

The success of IBM was indisputable all over the world including the Nordic countries in the field of administrative data processing in terms of sales, market dominance, number of customers, and hardware and software features. Just as indisputable was the failure of IBM to capture the scientific market in the Nordic countries. Towards the end of the period of early computing, some events promised to turn failure into success. The most important was the establishment of IBM Nordic laboratories in Stockholm in 1961. The laboratory employed a relatively large group of scientists from all over the Nordic countries. These scientists received training in other laboratories in Europe and USA and put to work on scientific problems as well as on practical product development. The scientific work included modern control theory and the products were mostly control systems. Many of the laboratory scientists later accepted important positions in Nordic universities in research institutions and in industry, carrying with them deep insights and pleasant memories from their time with IBM. 
Another act of IBM that rendered the company a lot of good will was the donation of a large-scale scientific computer to the Technical University of Denmark in Lyngby in 1964. The Northern Europe University Computer Center (NEUCC) grew from this computer to serve the Nordic scientific community, especially university scholars. At the same time, a fund was set up to give financial support to users traveling from their countries to the Center [6].

With regard to computer systems, the announcement of the IBM System 360 in 1964 with deliveries two years later was most significant for the entire market. The 360 offered a product line in which each single product was compatible up- and downward. With the computer came an entirely new operating system. The original intention was to make a computer that they could use for data processing and scientific computing. They did not entirely achieve this intention.

\subsection{Summing up scientific computing}

Even if IBM were not as successful in the scientific computing market as it was in the administrative data processing market, one might claim that it indirectly influenced the general market for scientific computing in the Nordic countries. One might point to the following influences:

- The vigorous IBM sales efforts, information activities, and publications paved the way for scientific computers of all brands. Many of these activities involved visiting specialists from other, more advanced, IBM establishments.

- Nordic university people and other members of the scientific community learnt computer basics while taking part in early IBM courses.

- Some of the Nordic universities took advantage of the generous rebates that IBM awarded for educational computer rentals.

- The fast growing and well-managed stock of application programs, for the IBM 650, for example, gave many scientific and engineering users a short cut to results instead of developing programs themselves.

- The initial IBM administrative computers were used for scientific and engineering applications by many outside users.

- Typical IBM programming languages such as FORTRAN was the base for more sophisticated programming systems developed in the Nordic countries.

- FORTRAN turned out to be the dominating programming language in the practical engineering market.

- A large number of Nordic scientists had early experience with largescale IBM scientific computers while studying at, or visiting, US 
Universities and research institutions or while using the IBM computing center in Paris or, later, the NEUCC in Lyngby, Denmark.

- The IBM Nordic Laboratories trained a large group of people from all over the Nordic countries to act as systems engineers, teachers, and managers in Nordic universities, institutions, and industries.

- The question: "Was IBM instrumental in wrecking the Nordic national computer industry?" can be answered yes and no. Yes, because IBM was too strong a company to beat by local start-ups. No, because of IBM had a strict and almost paranoid adherence to the restrictions set by anti-trust laws. However, with regard to the IBM sales representatives, one may suspect some hits below the belt. IBM was sometimes accused of "pre-announcing" their new products before they were ready, thereby holding up customers who were about to order from IBM's competitors.

IBM headquarters had specialists who acted when they heard about plans to establish national computer industries in a particular country. They offered cooperation, sub-contractorships, for example, as an alternative to starting a computer industry while warning of the high cost and risk involved in competing with IBM. I was aware of one such (unsuccessful) attempt by IBM in the case of Nokia in the early 1960s.

\section{EARLY COMPUTING IN NORDIC IBM COUNTRY BY COUNTRY}

\subsection{IBM Denmark}

The computer era started in Denmark with the building of an (improved) copy of the Swedish BESK, named DASK [5, 9]. It was ready for use in 1957 and installed at Regnecentralen. The Gier was the second machine built at Regnecentralen in 1960 .

The IBM era in data processing began in 1959 when Dansk Folke Forsikrings Anstalt (DFFA) ordered an IBM 7070. DFFA installed a 1410 machine in 1962. The same year, 1962, I/S Datacentralen installed an IBM 7070. The 1401 and its small brother 1440 were, however, the machines that dominated the administrative data processing market in Denmark during the early computing period before the advent of the IBM System 360 . Several 305 RAMACs were also installed, one of the first at Toms Fabrikker in 1960.

Just at the end of the era of early computing IBM made a significant contribution to the scientific and educational community. IBM donated an IBM 7090 computer to the Danish Technical University in Lyngby used by 
scientists in the Nordic countries plus the Netherlands. At the same time, IBM formed an endowment fund for supporting the users of the computer. The new computing center had the name Northern Europe University Computing Center (NEUCC) [6].

\subsection{IBM Finland}

The national project for building a computer (ESKO at 20 additions per second) in Finland started in 1955, much later than in Norway and Sweden [4]. This was not ready for use until 1960. At that time, the first computer in Finland, the IBM 650, was already installed (1958) at the Postal Savings Bank. The main applications were a number of typical banking data processing tasks, but from the beginning, the scientific community used the available extra computer time. Many of these scientists had started earlier by using the IBM 604 electronic calculator in Finland or the IBM 650 in Stockholm or Paris for their scientific tasks. Finnish universities installed a number of IBM 1620 machines. Regardless, the non-IBM computers outnumbered IBM ones at the Finnish universities. The universities received some of the non-IBM computers gratis. An IBM 1710 process control system was installed in 1963 at the Enso-Gutzeit Kaukopää paper mill. One of the IBM machines used solely for engineering calculations was the IBM 610 , based on paper tape, a magnetic drum, and 300 electron tubes plus electromechanical components, which was installed in 1959 at Valmet Rautpohja and Kunnallislaskenta.

In the administrative data processing market, IBM achieved the same dominating position as elsewhere in the world. After the first IBM 650 at the Postal Savings Bank followed a second IBM 650 and two IBM 305 RAMACs (installed at retail company Elanto and wholesale company OTK in 1959), and a horde of IBM 1401s and 1440s. The first 1401 was installed for the tax authorities in 1961. The largest machines installed in Finland before the IBM 360 era were several IBM 1410 systems.

\subsection{IBM Iceland}

The first computer came to Iceland in 1964 as the Icelandic State and Municipal Data Center obtained an IBM 1401 and the University of Iceland an IBM 1620 (obtained with a $60 \%$ educational allowance) [7, 8]. The year before, IBM had arranged for a demonstration of an IBM 1620 at the University. The first courses were held with support from IBM Denmark and gave people the opportunity of using the computer. The state government was of the opinion that these two computers should carry out all data processing and all scientific and engineering computing in Iceland. 
FORTRAN courses were offered locally and the IBM Program Library was taken advantage of. This situation lasted until the 1970s and 1980s when the "IBM monopoly" was broken. During the time before 1964, IBM punched card machines were extensively used in Iceland: the first Unit Record equipment came in 1949. The National Register was established in 1952. Some scientists had learned to use IBM computers at universities abroad.

\subsection{IBM Norway}

First in Norway was the Norwegian built computer NUSSE (500 additions per second). It was ready for use in 1954 [1]. The first and only IBM 650 computer in Norway was installed in Bergen in 1958 as a joint venture between the Bergen University and a group of local industries and the local tax authorities. In 1963, the University of Bergen ordered an IBM 1620. Only one 305 RAMAC was installed in Norway, at Freia Chocolade Fabrik A/S (1960). The 1401 definitely heralded the entry of IBM Norway into the electronic data processing world. In 1961, five 1401 machines were installed in Norway. The insurance company Storebrand installed a large 1410-1401 system with magnetic tapes in 1962. The IBM 1440, announced in 1962, was perfectly priced for the Norwegian market.

In 1963, ten out of twenty-five computer installed in Norway were used for statistical or scientific applications. In 1966, out of a total of 75 computer installations, IBM had installed 43. As to the number of systems on order in 1966, 52 out of 62 were ordered from IBM, most of them IBM System 360.

\subsection{IBM Sweden}

Scientific computing started in Sweden in 1954 when the first Swedish computer BESK (16 000 additions per second) was inaugurated $[2,3,5]$. It gave rise to a large family of computers at various universities in Sweden, Norway, and Germany. The first IBM 650 customers were Kungliga Flygförvaltningen, Folksam (1956) and Thule. The 650 machines were used in their spare time by scientific and data processing customers throughout the Nordic countries. The Swedish defense research institution (FOA) installed an IBM 7090 in 1961. A few 1620 computers were installed, one of them at the University of Umeå. The first 1710 process control system was installed at the Billerud Paper plant and another at LKAB (mining company in Kiruna) at the beginning of the 1960s. The IBM 1401 was introduced into the Swedish market in 1959 and marks the beginning of the growth period of IBM data processing in Sweden [2]. The Swedish Central Bureau of Statistics installed an IBM 7070 in the early 1960s, and some 
other 7000-series computer were installed as well. The IBM Nordic Laboratories was founded in 1960.

\section{REFERENCES}

1. Nerheim, Gunnar \& Nordvik, Helge W.: Ikke bare maskiner, Historien om IBM Norge 1935-1985, Stavanger 1986.

2. Pressmeddelande om IBMs 75 år i Sverige. http://www.ibm.com/news/se/2002/12/10ibm75.html

3. IBM Archives. http://www-1.ibm.com/ibm/history/

4. Tienari, Martti (ed.): Tietotekniikan alkuvuodet Suomessa (the first years of computing in Finland), Jyväskylä 1993.

5. Bruhn, Erik (ed.): EDB Historik - i nordisk perspektiv, Copenhagen 1991.

6. "Lyngby har fået elektronregnemaskine til 20 mill. kroner", Lyngby-Tårbäck Bladet 28.10.1965.

7. Oddur Benediktsson et al., Computerization of the Icelandic State and Municipalities in the years 1964 to 1985 , HINC-1 Abstract.

8. Magnús Magnússon, The advent of the first general purpose computer in Iceland and its impact on science and engineering, HINC-1 Abstract.

9. IBM NYT Bildkavalkade 1950-1975.

\section{ACKNOWLEDGEMENTS}

The author was employed by IBM in Finland, in the Nordic Regional Office in Stockholm and in the IBM Nordic Laboratory in various positions during the period 1956-1965 ending up as DP Sales Country Manager in IBM Finland. Many of the thoughts and memories presented above stem from that time. Without the help of present day IBMers who dug for information in the IBM archives, fellow IBMers from my time with the company, and fellow members of the HNC-1 Program Committee who supplied me with helpful information and contacts of various kinds, it would not have been possible to me to write this paper. 